\title{
A case of pica and elevated lead levels in a child
}

Graham Martin, Vishal Gupta, Habib Bhurawala

\section{CASE}

A boy aged 3.5 years presented to the paediatric clinic of a metropolitan teaching hospital with a 14-month history of pica and behavioural problems. He presented with hyperactivity; inattention; developmental delay including receptive and expressive language delay, motor delay, cognitive delay, delayed social skills and sensoryseeking behaviour; and, most notably, the mouthing of non-food objects including toilet paper, tyres of toy cars, pencils and pens. He was known to bite other children during playtime when overly excited. Behaviour modification strategies and speech and occupational therapy were recommended by the consulting paediatrician. Blood tests including full blood examination (FBE), iron studies and serum lead levels were also recommended.

\section{QUESTION 1}

What is pica?

\section{QUESTION 2}

How might a patient with pica present?

\section{QUESTION 3}

What are the diagnostic criteria for pica?

\section{QUESTION 4}

What is the epidemiology of pica, and where is it most commonly seen?

\section{ANSWER 1}

Pica is a medical and psychological condition in which an appetite for non-food, non-nutritive substances arises. There is a strong association with an iron deficiency, which is believed to drive the abnormal consumption. ${ }^{1}$

\section{ANSWER 2}

Pica in paediatric patients presents with non-specific generalised symptoms including chronic abdominal pain, headache, change in appetite and behavioural issues. ${ }^{2,3}$ Results showing iron deficiency anaemia ${ }^{1}$ or otherwise unexplained lead toxicity may point towards a diagnosis of pica; therefore, a thorough pica history and a high index of suspicion can help clinicians formulate a diagnosis.

\section{ANSWER 3}

A formal diagnosis of pica requires all Diagnostic and statistical manual for mental disorders, 5 th edition, criteria to be met; the patient would be eating non-nutritive substances over the period of at least one month, and this is determined to be inappropriate for the current developmental stage of the patient and not culturally supported. Where the eating behaviour occurs in conjunction with another medical condition including pregnancy or mental disorder, it warrants further investigation. ${ }^{4,5}$

\section{ANSWER 4}

Pica most often occurs during childhood; however, it can occur at any age. The prevalence is unknown; however, it is suspected that pica occurs more frequently in patients with developmental, behavioural or intellectual disabilities. ${ }^{5}$

\section{CASE CONTINUEd}

The boy was reviewed four months later. His speech had improved; he was able to construct short sentences with poor pronunciation. His attention and hyperactivity remained, and he continued to eat non-food objects. His parents were reluctant to have the blood tests completed after his initial paediatric appointment. However, they eventually arranged for his blood tests to be completed nearly three weeks before his follow-up appointment in the paediatric clinic. The results showed an elevated lead level of $9.4 \mu \mathrm{g} / \mathrm{dL}(0.45 \mu \mathrm{mol} / \mathrm{L})$, with the normal range $<5 \mu \mathrm{g} / \mathrm{dL}(0.24 \mu \mathrm{mol} / \mathrm{L})$. Other blood tests were unremarkable, including FBE and iron studies. The public health unit was notified about the patient's elevated serum lead levels, and a public health unit team member had contacted the family before his follow-up appointment; however, a source for the lead was unclear. No additional treatment was recommended for the elevated lead level by the public health unit as they explained that, in most cases, serum lead level usually normalises after elimination of exposure.

\section{QUESTION 5}

At what ages are high lead levels most likely to be detrimental to health, and with what symptoms might a paediatric patient present? 


\section{ANSWER 5}

Elevated lead levels are detrimental to patients of any age when they persist for long periods of time. Those most at risk include fetuses, infants and children up to five years of age because of their rapid neurodevelopment. ${ }^{2}$

Children can present with non-specific symptoms including abdominal pain, headaches, loss of appetite and constipation, or they may be asymptomatic and be found to have significantly elevated serum lead levels. ${ }^{2,6}$ However, even low serum lead levels within the normal range of $<5 \mu \mathrm{g} / \mathrm{dL}(0.24 \mu \mathrm{mol} / \mathrm{L})$ can affect neurodevelopment, resulting in cognitive impairment, IQ decrement and changes in behaviour including inattention, impulsivity, aggression and hyperactivity. ${ }^{\text {? }}$

It should be noted that a child with lead toxicity will present very differently to an adult with lead toxicity, who is more likely to present with neuropathy, renal disease and hypertension, depending on the toxicity level and the duration of their elevated lead levels. In contrast, children tend to experience effects on their central nervous system. ${ }^{8}$

\section{CASE CONTINUED}

The boy was reviewed a further four months later. His behavioural problems persisted. He had been formally diagnosed with attention deficit hyperactivity disorder (ADHD), speech delay and atypical sensory-seeking behaviour, including putting non-food objects in his mouth and biting his nails. He did not have a diagnosis of autism spectrum disorder, and his intellectual function was in the average range. Serum lead levels remained high at $8.9 \mu \mathrm{g} / \mathrm{dL}$ $(0.43 \mu \mathrm{mol} / \mathrm{L})$.

\section{QUESTION 6}

What should be done in primary care if a child is found to have elevated serum lead levels?

\section{ANSWER 6}

Management of a patient with elevated lead levels is based on the degree of elevation and will include:
- identification and removal of the lead source - children's toys are a common source of lead poisoning in children ${ }^{9}$

- allied health services - these can help with behaviour modification in a child with pica

- discussion with clinical toxicologist/ public health

- serial monitoring of blood lead levels

- management with chelation if levels are above $45 \mu \mathrm{g} / \mathrm{dL}(2.17 \mu \mathrm{mol} / \mathrm{L}){ }^{2}$

\section{CASE CONTINUED}

On review three months later, the patient had ongoing behavioural issues, ADHD, speech delay and sensory-seeking behaviour (without autism spectrum disorder). He was still biting his nails and hands but was no longer eating non-food objects; his lead level had decreased to $7.6 \mu \mathrm{g} / \mathrm{dL}(0.36 \mu \mathrm{mol} / \mathrm{L})$. He continued to be a fussy eater but had begun to try new foods. Services involved in his care included speech pathology, occupational therapy, day care and early education playgroup.

\section{Key points}

- Pica is more likely to present in children with complex health conditions.

- Younger children show a global developmental delay, sensory processing disorders, complex behavioural and developmental disabilities, whereas school-aged children present with intellectual disability, autism, ADHD and anxiety.

- It is important to consider the cause and effect of pica and investigate appropriately, remembering that iron deficiency anaemia can be one of the drivers for pica.

- Management of elevated lead levels in children includes removing the source, discussing the elevated lead levels with a clinical toxicologist and local public health unit team, serial monitoring of lead levels and considering chelation in severely elevated cases.

\section{Authors}

Graham Martin MBBS, Foundation Doctor, East Kent Hospitals University NHS Foundation Trust, UK
Vishal Gupta MBBS, FRACP, Paediatric Staff Specialist, Nepean Hospital, NSW

Habib Bhurawala MBBS, MD, DCH, AFRACMA, FRACP, Head of Paediatric Department, Nepean Hospital, NSW; Conjoint Clinical Lecturer, Discipline of Paediatrics, University of Sydney Nepean Clinical School, NSW

Competing interests: None.

Funding: None.

Provenance and peer review: Not commissioned, externally peer reviewed.

Correspondence to:

graham.martin@doctors.org.uk

\section{References}

1. Mehta A. Iron deficiency anaemia. London: BMJ Best Practice, 2020. Available at https:// bestpractice.bmj.com/topics/en-gb/94 [Accessed 24 July 2020].

2. NSW Health. Lead in blood control guideline. St Leonards, NSW: NSW Ministry of Health, 2018. Available at www.health.nsw.gov.au/Infectious/ controlguideline/Pages/lead.aspx [Accessed 24 July 2020].

3. Reigart JR. Lead toxicity. London, UK: BMJ Best Practice, 2018. Available at https://bestpractice. bmj.com/topics/en-gb/755 [Accessed 24 July 2020].

4. American Psychiatric Association. Feeding and eating disorders. In: Diagnostic and statistical manual of mental disorders (DSM-5). 5th edn. Arlington, VA: APA, 2013.

5. Yager, J. Eating disorders: Overview of epidemiology, clinical features, and diagnosis. Waltham, MA: UpToDate, Inc, 2020. Available at www.uptodate.com/contents/ eating-disorders-overview-of-epidemiologyclinical-features-and-diagnosis?search $=P I C A \& s$ ource=search_result\&selectedTitle=1 48\&usage type $=$ default $\&$ display_rank $=1$ [Accessed 24 July 2020].

6. Hauptman M, Bruccoleri R, Woolf AD. An update on childhood lead poisoning. Clin Pediat Emerg Med 2017;18(3):1818-92. doi: 10.1016/j. cpem.2017.07.010.

7. Lanphear BP, Lowry JA, Ahdoot S, et al. Prevention of childhood lead toxicity. Pediatrics 2016;138(1):e20161493. doi: 10.1542/peds.20161493.

8. Agency for Toxic Substances \& Disease Registry Lead toxicity: What are possible health effects from lead exposure? Atlanta, GA: ATSDR, 2019. Available at www.atsdr.cdc.gov/csem/csem. asp?csem $=34 \& p o=10$ [Accessed 18 May 2020].

9. Department of Health, Western Australia. Lead exposure. Perth, WA: Department of Health, [date unknown]. Available at https://healthywa. wa.gov.au/Articles/JM/Lead-exposure [Accessed 20 May 2020]. 